\title{
Tele-Dermatology in Clinical Management of Suspected Cutaneous Leishmaniasis in COVID-19 Pandemic
}

\section{Paudel V ${ }^{1}$}

${ }^{1}$ Lecturer, National Medical College, Birgunj, Nepal.

\begin{abstract}
:
The COVID-19 pandemic has changed the world dynamics in various prospects. It led to the restricted mobility of dermatological patients and helped telemedicine platform to flourish than ever. Though teledermatology has its own pros and cons, it's being used in treatment of various skin disorders. Cutaneous leishmaniasis is an emerging disease in Nepal whose diagnosis is primarily clinical and histological. We are reporting a case of suspected cutaneous leishmaniasis from far western hilly region of Nepal who was empirically treated with fluconazole with the help of teledermatology platform with outstand outcomes.
\end{abstract}

Key words: COVID-19; Fluconazole; Leishmaniasis, Cutaneous; Pandemics; Telemedicine

\section{Dear Editor,}

$\mathrm{T}$ he world is changing dramatically with COVID19 pandemic with novel challenges even for dermatologists. ${ }^{1}$ As mobility is restricted, it is impossible for the patients to visit the dermatologists. Thus, teledermatology has grown up in the scenario and is more frequently used. Teledermatology has pros and cons in management of various skin related disorders. Thus, the clinical history, photographic images and videos via teledermatology has been the cornerstone of diagnosis rather than sophisticated investigations. ${ }^{2}$ As the editorial in 2018(1) had focused about the emerging nature of cutaneous leishmaniasis (CL), we would like to emphasize about teledermatology in $\mathrm{CL}$ in current pandemic. ${ }^{3}$

$\mathrm{CL}$ is a vector-borne infection presenting as crusted lesions at inoculation site where diagnosis is primarily clinico-histopathological. ${ }^{4}$ There are reports of $\mathrm{CL}$ cases from different hilly regions of Nepal without travel history to arid areas. ${ }^{5-7}$ The diagnosis of $C L$ is clinical and confirmed by demonstration of amastigote, leishmanial granulomas, growth of promastigotes

Financial disclosure: None.

Conflict of interest to disclosure: None declared.

Address of Correspondence

Dr. Vikash Paudel, MBBS, MD

Lecturer

National Medical College

Birgunj, Nepal.

E-mail: vikashpoudel@iom.edu.np in Nicolle-Novy-macNeal (NNN) medium or demonstration of leishmanial DNA. ${ }^{4}$

We are reporting a teledermatology consultation case of suspected $\mathrm{CL}$ without confirmatory diagnosis, and treated with fluconazole with outstanding results. A twelve-year boy from far-western hilly region had asymptomatic, progressive growth of crusted indurated plaques, three in number (size $1 \times 1 \mathrm{~cm}$ to $2 \times 2 \mathrm{~cm}$ ) over the chin and lips for two months. There was no history of fever, cough or any medical illness, no history of travel, trauma, drug use, and no history of similar illness or any family history. The lesions were studied through serial photographs, videos and assisted paramedics examinations. Because of the clinico-epidemiological aspect, $\mathrm{CL}$ was suspected the most likely. The points in favor of diagnosis were clinical findings, asymptomatic, crusted and indurated plaques over the face which were of two months' duration, geographical location of $\mathrm{CL}$ emerging areas.

Submitted: $6^{\text {th }}$ July 2020

Accepted: $27^{\text {th }}$ July 2020

Published: $7^{\text {th }}$ October 2020

How to cite this article

Paudel V. Tele-dermatology in clinical management of suspected cutaneous leishmaniasis in COVID-19 pandemic. Nepal Journal of Dermatology, Venereology and Leprology 2020;18(1): 91-2. https://doi.org/10.3126/njdvl.v18i1.31120.

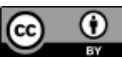

Licensed under CC BY 4.0 International License which permits use, distribution and reproduction in any medium, provided the original work is properly cited. 
However still, the definitive diagnosis could not be made without histopathology or molecular diagnosis. With the provisional diagnosis of $\mathrm{Cl}$, the patient was put under empirical therapy with anti-leishmanial and antifungal drug i.e., fluconazole $150 \mathrm{mg}$ twice daily. During close monitoring, the patient was responding to fluconazole properly. The results were outstanding, shown in serial photographs taken one month apart. (Figure) Though the response of systemic fluconazole supports our provisional diagnosis of $\mathrm{CL}$, we could not absolutely deny other differentials without strong supportive evidence. The closest differential could be sporotrichosis, but occupation of patient, no history of injury in face and response with lower dose of fluconazole help us to shift the diagnosis more toward $\mathrm{CL}$.

Thus, this report might support $\mathrm{CL}$ is an emerging disease in the hilly areas of Nepal. A good teledermatology platform could help in managing $\mathrm{CL}$, if we have thoughtful clinical mind.
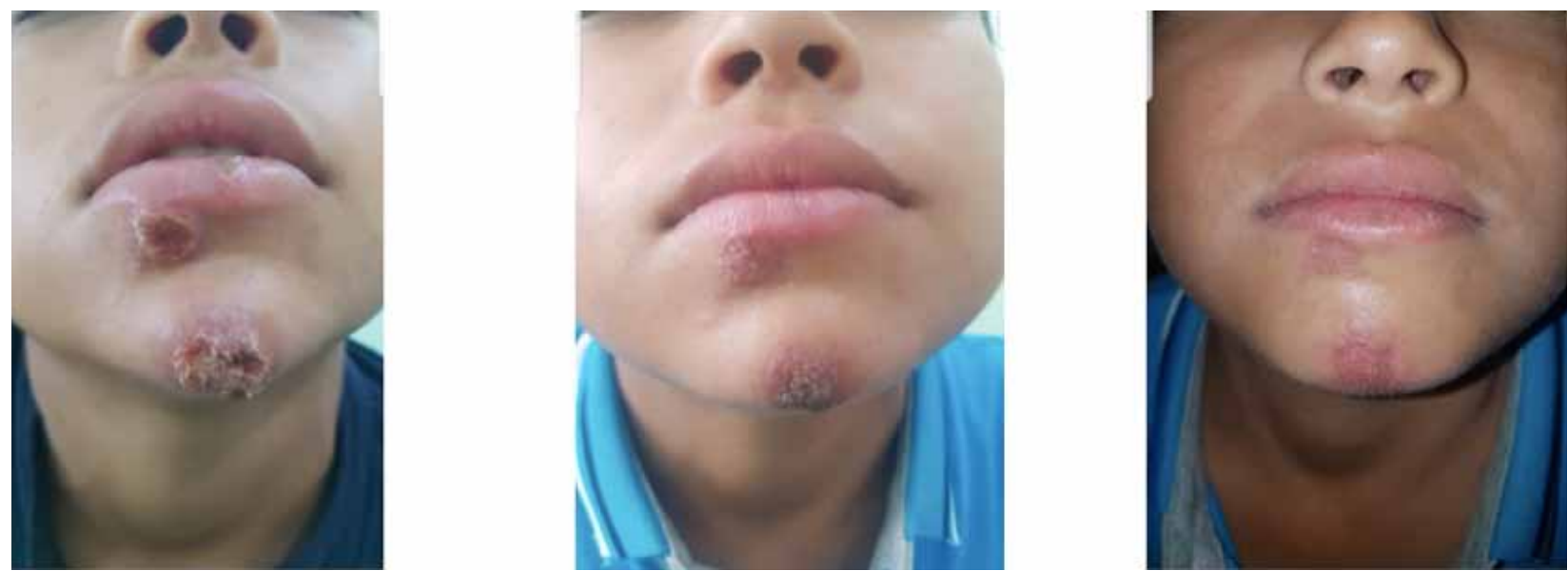

Figure: Three consecutive picture of cutaneous leishmaniasis in the face (chin and lip) of a boy at one month apart.

\section{References}

1. Adams JG, Walls RM. Supporting the health care workforce during the COVID-19 global epidemic. JAMA 2020;323(15):1439-40. https://doi. org/10.1001/jama.2020.3972

2. Perkins $S$, Cohen JM, Nelson CA, Bunick CG. Teledermatology in the era of COVID-19: Experience of an academic department of dermatology. J Am Acad Dermatol 2020;83(1):e43-e44. https://doi.org/10.1016/j. jaad.2020.04.048

3. Neupane, S. Cutaneous Leishmaniasis: Revisited. Nepal Journal of Dermatology, Venereology and Leprology 2018;16(1):1. https://doi.org/10.3126/ njdvl.v16i1.19396
4. Adhikari RC, Shah M. Cutaneous leishmaniasis. Journal of Pathology of Nepal 2017;7:1212-7. https://doi.org/10.3126/jpn.v7i2.18031

5. Paudel V, Parajuli S, Chudal D. Cutaneous leishmaniasis in Nepal: an emerging public health concern. Our Dermatology Online 2020;11(1):1-3. https://doi.org/10.7241/ourd.20201.20

6. Paudel U, Parajuli S, Paudel AS, Paudel V, Pokhrel DB. Cutaneous leishmaniasis in natives of Central Region of Nepal. Kathmandu Univ Med J. 2019;65:79-81.

7. Ghimire P, Shrestha R, Pandey S, Pokhrel K, Pande R. Cutaneous Leishmaniasis: A neglected vector borne tropical disease in mid-western region of Nepal. Nepal Journal of Dermatology, Venereology and Leprology 2018;16(1):41-4. https://doi.org/10.3126/njdvl.v16i1.19405 